\title{
Light emitting diode enhances the biomass yield and antioxidant activity of Philippine wild mushroom Lentinus swartzii
}

\author{
Reyna C. Tiniola1, Raquel C. Pambid¹, Adonis S. Bautista1, Rich Milton R. Dulay ${ }^{*}$ \\ ${ }^{1}$ School of Advanced Studies, Pangasinan State University, Urdaneta City, Pangasinan, Philippines \\ ${ }^{2}$ Bioassay Laboratory, Department of Biological Sciences, College of Science, Central Luzon State University, Science City \\ of Muñoz, Nueva Ecija, 3120 Philippines
}

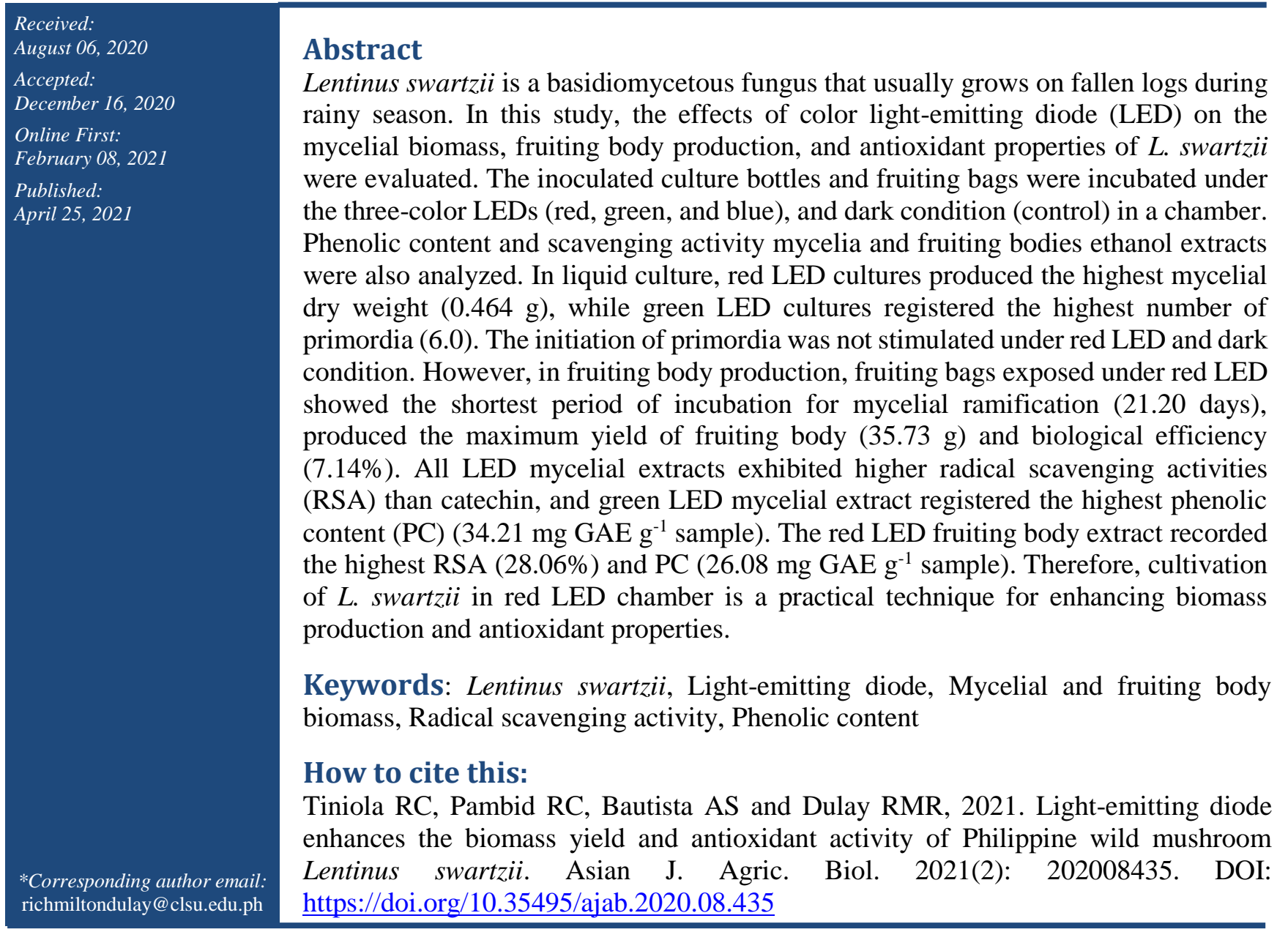

This is an Open Access article distributed under the terms of the Creative Commons Attribution 3.0 License. (https://creativecommons.org/licenses/by/3.0), which permits unrestricted use, distribution, and reproduction in any medium, provided the original work is properly cited.

\section{Introduction}

The Philippines is known to have very diverse mycological resources, particularly mushrooms that are naturally found growing on leaf litters, soil, stumps, tree trunks, fallen logs, termite mound, lawns, meadows and gardens. The period of May to September is believed to be the best time to collect mushrooms in the wild, which are basically for food. Mushrooms have been valued as nutritious food and 
are effective natural alternative for various diseases. They are ideal source of proteins, carbohydrates, crude fibers, fats, vitamins, minerals, and mycochemicals such as saponins, alkaloids, flavonoids, anthraquinones, athrones, phenols, steroids, coumarins, and fatty acids (Ghorai et al., 2009; Beluhan and Ranogajec, 2011; Sogan et al., 2018; Dulay and Pamiloza, 2018; Aquino et al., 2018). Mushroom extracts and bioactive components have been shown to exhibit antiviral, antiparasitic, antitumor, anticancer, antioxidant, antifungal, antibacterial, immunomodulatory, anti-inflammatory, antidiabetic, nephroprotective, neuroprotective and hepatoprotective properties (Wasser, 2002; Wasser and Weis, 1999). Moreover, mushrooms are also being used in agro-industrial wastes management (Philippoussis et al., 2011; Dulay et al., 2012a).

With the increasing demand for mushrooms, practical and economical production technologies have been developed by the Center for Tropical Mushroom Research and Development in Central Luzon, Philippines with the intention to improve their biological efficiency, thereby, increasing their production. These technologies include the zero-rice waste technology, tilapia and mushroom growth chamber system, aseptic cultivation technology, submerged culture using liquid media, and agroindustrial wastes utilization in mushroom production. However, in Malaysia, electrical shock, bright light, cold temperature $\left(5^{\circ} \mathrm{C}\right)$ and high intensity of sound were found effective physical treatments in promoting spawn running and pinhead formation, and in increasing the productivity of Pleurotus sajor-caju (Ibrahim et al., 2015). Further, it was demonstrated that the different acoustic sound treatments at $75 \mathrm{~dB}$ enhanced the productivity and growth of mycelia of the same mushroom (Ibrahim et al., 2017).

Light is an important energy source on earth. It can regulate growth, growth direction, reproduction, and formation of pigment which is necessary for the survival and distribution of fungi (Idnurm and Heitman, 2005). Illumination is also one of the important environmental requirements in the growth and development of mushrooms. The presence of light stimulates the mycelial growth of Schizophyllum commune, Volvariella volvacea, Lentinus sajor-caju and Lentinus tigrinus (Kalaw et al., 2016; Dulay et al. 2012b; Reyes et al. 1998). Light-emitting diode (LED) has high energy efficiency and it does not emit heat rays, which is more advantageous than fluorescent lamps (Jang et al., 2013). Literature proves that blue
LED improves the growth and production of mycelial and basidiocarp, and antioxidant activity of L. tigrinus (Damaso et al., 2018), while red LED enhances the mycelial biomass yield and phenolic content of Ganoderma lucidum (Alcazar et al., 2018), which indicate that mushrooms respond differently to LED.

Lentinus swartzii, which belongs to the Family Polyporaceae, is a newly cultivated mushroom in the Philippines. Fruiting bodies of this mushroom have generally light-coloured pileus with dense brown to black smooth scales and are characterized to have leathery stipe. The wild strain is found growing gregariously on dead wood of mango (Mangifera indica) in Central Luzon region. Unlike other Lentinus, reports about this species are very limited. Studies on the culture conditions and functionality profile of $L$. swartzii are currently under investigation in our laboratory. Recently, we reported the nutritional requirements for mycelial growth and the basidiospore germination and morphogenesis of L. swartzii (Dulay et al., 2020a; 2020b). The optimum culture conditions, biomass production, nutritional compositions, biological activities of its relative, L. tigrinus, have been reported in various studies (Dulay et al., 2012b; 2012c; 2014; 2015; 2017a; 2017b; Ragasa et al., 2018). On this note, L. swartzii potentially demonstrates the same properties, hence further study is necessary.

Herein, we aimed to investigate the effects of color LED on the mycelial biomass production, fruiting body production, antioxidant property of $L$. swartzii in our desire to generate effective technique for efficient biomass production of this mushroom with antioxidant properties.

\section{Material and Methods}

\section{Mushroom culture}

Mycelial culture of $L$. swartzii from the collections of Bioassay Laboratory, Department of Biological Sciences, College of Science, Central Luzon State University, Science City of Muñoz, Nueva Ecija, Philippines was used in this study. The mushroom was cultured in potato dextrose agar plates for five days, which served as source of mycelial inoculant in the growth performance assays.

\section{Evaluation of mycelia biomass production}

In this study, the effect of color LEDs on the production of mycelia of $L$. swartzii in submerged culture condition 
was assessed. Coconut water was used as liquid medium. Fifty $\mathrm{ml}$ of coconut water was dispensed into each transparent glass bottle with cotton plug. A total of 20 bottled media was prepared. These were sterilized at $15 \mathrm{psi}, 121^{\circ} \mathrm{C}$ for $20 \mathrm{~min}$ in an autoclave. When cooled, each bottled medium was inoculated with $10 \mathrm{~mm}$ diameter discs of mycelia from the 5-day old culture. The inoculated bottled media were incubated in the LED chamber for 15 days. Five bottles were placed in each treatment. After incubation, mycelia mats were harvested, air-dried and weighed. The number of initiated primordia was recorded. The final volume of the spent media was also recorded. The air-dried mycelia were subjected to ethanol extraction for antioxidant and total phenolic analyses.

\section{Evaluation of fruiting body production}

The preparation of grain spawn and substrate formulation using sawdust and rice straw for fruiting body production of $L$. swartzii were the same as the previous report on L. tigrinus (Dulay et al., 2012b). A total of 20 bags were prepared. The bags were sterilized at $15 \mathrm{psi}, 121^{\circ} \mathrm{C}$ for one hour. Forty grams of the grain spawn were inoculated into each bag and placed in the LED chamber for incubation until the full mycelial ramification. Five bags were placed in each treatment. The period of incubation was recorded. Fruiting bags were opened and watered to allow primordial development and eventually develop into mature fruiting bodies. The yield and biological efficiency were determined. The fruiting bodies were air-dried, pulverized, and were subjected to ethanol extraction for the assays.

\section{Ethanol extraction}

Five grams of pulverized mycelia and fruiting bodies of $L$. swartzii were soaked in $250 \mathrm{ml}$ of $95 \%$ ethanol. After 48 hours, filtration was done using Whatman filter No. 2, and the ethanol was separated from the extract through rotary evaporation. The yield extracts were placed separately in vials and were refrigerated until needed for the assay.

\section{Antioxidant activity assay}

The standard method of Kolak et al. (2006) on scavenging activity assay using the stable 2, 2'diphenyl-1-1picrylhydrazyl (DPPH) was used to determine the antioxidant activities of the extracts. The DPPH radical scavenging activity (RSA) of the extracts was calculated based on the absorbance reading at $517 \mathrm{~nm}$ using a UV VIS spectrophotometer
(Spectrumlab 752S, Hinotek Instrument Co., LTD, China). On the other hand, phenolic content (PC), in gallic acid equivalents (GAE), of the extracts was determined using Folin-Ciocalteu method (Sunita and Dhananjay, 2010) and was calculated based on the absorbance reading at $760 \mathrm{~nm}$ using a UV VIS spectrophotometer.

\section{Statistical analysis}

Analysis of Variance (ANOVA) and Least Significant Difference (LSD) at 5\% significance level in SAS System Version 9.0 were used to analyze the data.

\section{Results}

\section{Effect of color LED on mycelial biomass production}

The effects of color LED on the mycelial biomass production of $L$. swartzii were evaluated. The mycelial dry weight, volume loss of culture spent, and number of primordia are presented in Table 1. Among treatments, red LED recorded the highest mycelial dry weight $(0.464 \mathrm{~g})$. However, the other two color LEDs registered lower mycelial dry weight, which was comparable to dark condition. Surprisingly, color LED also stimulated the initiation of primordia in liquid culture. It can be noted that green LED recorded the highest number of primordia, followed by the blue LED. However, no primordium was observed in those incubated under red LED and dark condition. Figure 1 shows the liquid cultures of $L$. swartzii as affected by the color LEDs and dark condition. In terms of the volume loss of culture spent, no significant difference was observed among treatments, indicating that the utilization of liquid media by mushroom was not affected by LED.

Table-1. Mean mycelial weight, number of primordia, and volume loss of culture spent of Lentinus swartzii grown in liquid culture using coconut water after 15 days of incubation in color LEDs.

\begin{tabular}{|c|c|c|c|}
\hline Treatment & $\begin{array}{c}\text { Mycelial } \\
\text { Weight }(\mathbf{g} \text { dry } \\
\text { wt.) }\end{array}$ & $\begin{array}{c}\text { Number of } \\
\text { primordia }\end{array}$ & $\begin{array}{c}\text { Volume loss } \\
(\mathbf{m l})\end{array}$ \\
\hline Blue LED & $0.412 \pm 0.013^{\mathrm{b}}$ & $3.20 \pm 0.45^{\mathrm{b}}$ & $18.50 \pm 0.61^{\mathrm{a}}$ \\
\hline Red LED & $0.464 \pm 0.011^{\mathrm{a}}$ & $0.00 \pm 0.00^{\mathrm{c}}$ & $19.00 \pm 1.00^{\mathrm{a}}$ \\
\hline Green LED & $0.416 \pm 0.013^{\mathrm{b}}$ & $6.00 \pm 2.83^{\mathrm{a}}$ & $17.90 \pm 1.39^{\mathrm{a}}$ \\
\hline Dark condition & $0.422 \pm 0.008^{\mathrm{b}}$ & $0.00 \pm 0.00^{\mathrm{c}}$ & $18.10 \pm 0.74^{\mathrm{a}}$ \\
\hline
\end{tabular}

Values are mean \pm SD of five replicates. Means having the same letter of superscript in the same column are 
not significantly different from each other at $5 \%$ level of significance.

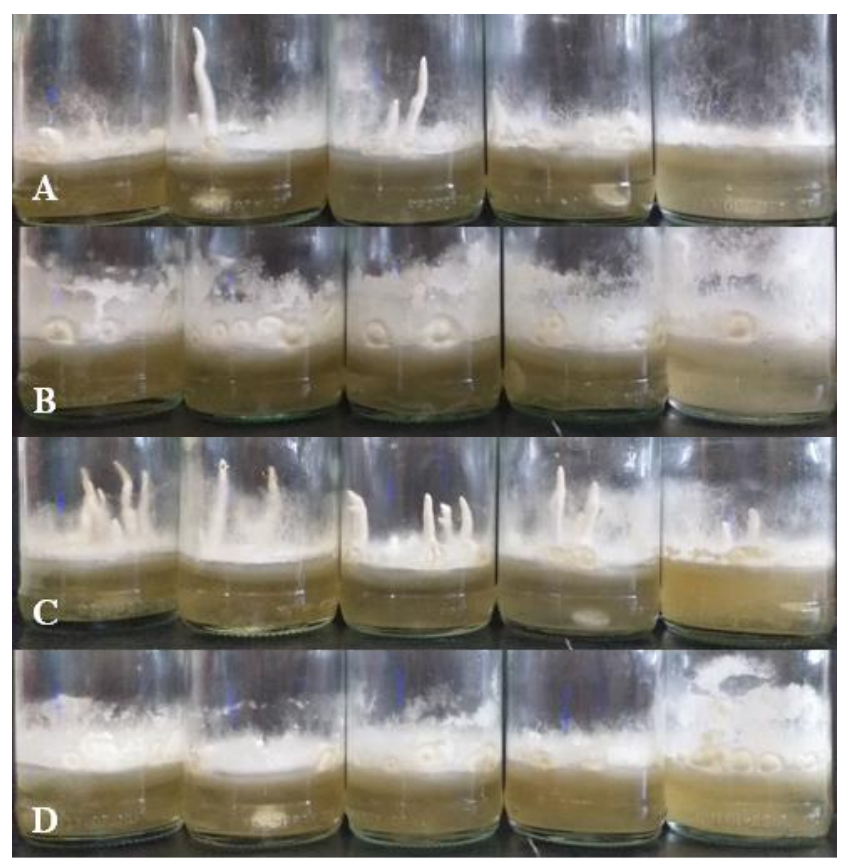

Figure-1. Liquid cultures of Lentinus swartzii exposed in color LEDs (A): blue LED, (B): red LED, (C): green LED and (D): dark after 15 days of incubation.

\section{Effect of color LED on fruiting body production} The effects of color LEDs on the ramification of mycelia and production of basidiocarp of $L$. swartzii were also investigated (Table 2). Apparently, the shortest period of incubation for mycelial ramification was observed in those incubated under red LED $(21.20$ days), but statistically comparable to those under blue LED and dark condition. In contrast, the extensive period for mycelial ramification was noted in green LED. The mean weight of fruiting bodies of $L$. swartzii is also presented in Table 2. Noticeably, the fruiting bags exposed under red LED produced that highest weight of fruiting bodies ( $35.73 \mathrm{~g})$, which corresponds to a biological efficiency of $7.14 \%$. However, no significant difference was found on the yields of red and blue LEDs. The lowest yield, on the other hand, was recorded in those grown under dark condition, which was statistically comparable to those under green LED. Figure 2 depicts the fruiting bodies grown on the substrate as affected by the different treatments.
Table-2. Mean number of day of mycelial ramification, weight of fruiting body, and percentage biological efficiency of Lentinus swartzii grown on rice strawsawdust based substrate in color LEDs.

\begin{tabular}{|l|c|c|c|}
\hline \multicolumn{1}{|c|}{ Treatment } & $\begin{array}{c}\text { Mycelial } \\
\text { ramification } \\
\text { (day) }\end{array}$ & $\begin{array}{c}\text { Weight of } \\
\text { fruiting bodies } \\
\text { per bag }(\mathbf{g})\end{array}$ & $\begin{array}{c}\text { Biological } \\
\text { Efficiency } \\
(\%)\end{array}$ \\
\hline Blue LED & $22.40 \pm 0.55^{\mathrm{ab}}$ & $32.54 \pm 1.84^{\mathrm{a}}$ & 6.51 \\
\hline Red LED & $21.20 \pm 0.45^{\mathrm{b}}$ & $35.73 \pm 1.58^{\mathrm{a}}$ & 7.14 \\
\hline Green LED & $23.00 \pm 0.71^{\mathrm{a}}$ & $23.58 \pm 1.79^{\mathrm{b}}$ & 4.72 \\
\hline Dark condition & $22.40 \pm 0.89^{\mathrm{ab}}$ & $21.35 \pm 3.66^{\mathrm{b}}$ & 4.27 \\
\hline
\end{tabular}

Values are mean \pm SD of five replicates. Means having the same letter of superscript in the same column are not significantly different from each other at $5 \%$ level of significance.

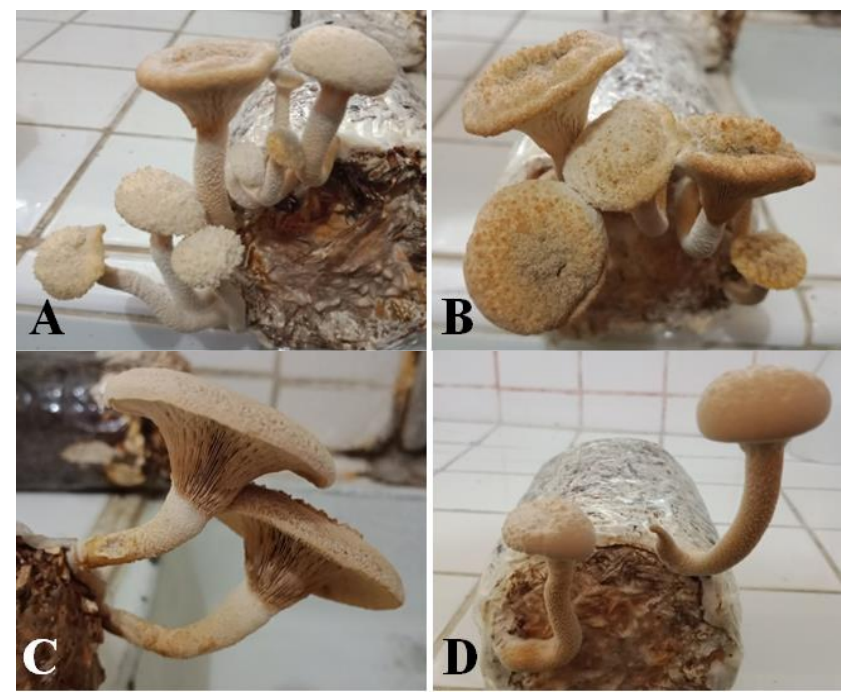

Figure-2. Fruiting bodies of Lentinus swartzii grown on rice straw-sawdust based substrate incubated in color LEDs (A): blue LED, (B): red LED, (C): green LED and (D): dark.

\section{Antioxidant activity of mycelia and fruiting body extracts}

The RSA and PC of mycelial and fruiting body extracts of $L$. swartzii are presented in Table 3. Apparently, extract of mycelia grown under red LED had the highest RSA of $73.95 \%$, but statistically comparable to the mycelial extracts from blue and green LEDs. In terms of PC, mycelial extract from green LED had the highest PC of $34.21 \mathrm{mg} \mathrm{GAE} \mathrm{g}^{-1}$ sample. Mycelial extract from dark condition significantly recorded the lowest RSA and PC. However, among ethanolic extracts of fruiting bodies, red LED recorded the highest RSA $(28.06 \%)$ and PC (26.08 $\mathrm{mg} \mathrm{GAE} \mathrm{g}^{-1}$ sample). Blue and green LEDs showed the minimum RSA and PC, respectively. 
Table-3. Radical scavenging activity and total phenolic content of ethanolic extracts of mycelia and fruiting body of Lentinus swartzii exposed in color LEDs.

\begin{tabular}{|c|c|c|c|c|}
\hline \multirow{3}{*}{ Extract } & \multicolumn{2}{|c|}{$\begin{array}{c}\text { Radical Scavenging } \\
\text { Activity (\%) }\end{array}$} & \multicolumn{2}{c|}{$\begin{array}{c}\text { Total Phenolic } \\
\text { Content (mg GAE / g } \\
\text { sample) }\end{array}$} \\
\cline { 2 - 5 } & Mycelia & $\begin{array}{c}\text { Fruiting } \\
\text { body }\end{array}$ & Mycelia & $\begin{array}{c}\text { Fruiting } \\
\text { body }\end{array}$ \\
\cline { 2 - 5 } & $72.26 \pm$ & $25.18 \pm$ & $26.71 \pm$ & $14.83 \pm$ \\
Blue LED & $1.28^{\mathrm{a}}$ & $0.42^{\mathrm{c}}$ & $0.52^{\mathrm{b}}$ & $0.64^{\mathrm{b}}$ \\
\hline \multirow{2}{*}{ Red LED } & $73.95 \pm$ & $28.06 \pm$ & $26.08 \pm$ & $26.08 \pm$ \\
& $0.49^{\mathrm{a}}$ & $0.83^{\mathrm{b}}$ & $0.64^{\mathrm{b}}$ & $0.84^{\mathrm{a}}$ \\
\hline Green & $73.11 \pm$ & $27.34 \pm$ & $34.21 \pm$ & $9.63 \pm$ \\
LED & $2.22^{\mathrm{a}}$ & $0.42^{\mathrm{bc}}$ & $0.32^{\mathrm{a}}$ & $0.63^{\mathrm{c}}$ \\
\hline Dark & $59.66 \pm$ & $26.62 \pm$ & $24.21 \pm$ & $9.83 \pm$ \\
condition & $0.84^{\mathrm{b}}$ & $1.10^{\mathrm{bc}}$ & $0.55^{\mathrm{c}}$ & $0.42^{\mathrm{c}}$ \\
\hline \multirow{2}{*}{ Catechin } & $60.50 \pm$ & $69.06 \pm$ & & - \\
& $2.95^{\mathrm{b}}$ & $1.10^{\mathrm{a}}$ & - & - \\
\hline
\end{tabular}

Values are mean \pm SD of triplicate tests. Means having the same letter of superscript in the same column are not significantly different from each other at $5 \%$ level of significance.

\section{Discussion}

The mycelial growth of mushroom is not only influenced by the nutritional factors but also by physical conditions such as light. According to Ambra et al. (2004), morphogenesis of organisms is stimulated by light. It has been reported also that light is very vital in the accumulation and formation of food reserves necessary for the development of mycelia into basidiocarp (Chang and Miles, 2004). The present study demonstrated that, among color LEDs used, red LED was found to be the most favourable light condition for the efficient mycelial biomass production. However, green and blue LEDs stimulated the formation of primordia of L. swartzii in the liquid culture condition. Likewise, the most efficient growth and production of mycelial biomass of Ganoderma lucidum was found in red LED (Alcazar et al., 2018). G. lucidum mycelia grew faster in red LED, blue LED and dark condition than under other light qualities (Wang et al., 2011). Moreover, red LED induced the conidiation of Beuaveria bassiana, in which the produced conidia were highly tolerant to ultraviolet radiation and induced sporulation in Physarum polycephalum ((Pittarate et al., 2018; Starostzik and Marwan, 1995). The suitability of red LED to the different above-mentioned fungal species is probably because red light is the basal component in lighting spectra, in which sole red light is sufficient for normal plant growth and photosynthesis (Olle and Virsille, 2013). The difference in the mycelial growth response of $L$. swartzii to color LED could be due to the quality of light requirement of mycelia of mushroom.

Light promotes the development of basidiocarp of mushrooms. The results of the present study indicate that red LED could promote mycelial ramification of L. swartzii in the substrate. However, Saadatmand et al. (2014) reported that the shortest period of incubation of Pleurotus florida is acquired when incubated under dark condition. In addition, L. tigrinus mycelia showed favourable response to blue LED (Damaso et al., 2018). Red LED was found to be the most favourable LED for fruiting body production of L. swartzii. Some cultivated mushrooms are also reported to show positive response to LED. For instance, Kim et al. (2012) posited that the pileus color intensity and stipe length of $P$. eryngii were affected grown under red, green, and mixed light $\left(R^{*} \mathrm{G}\right)$. In contrast to the present results, Damaso et al. (2018) reported that blue LED is the most favourable illumination condition for fruiting body production of L. tigrinus. It is safe to mention therefore that mushrooms, even belonging to same genus, have different responses to color LED.

Mushrooms exhibit different antioxidant properties, depending on the bioactive compounds and antioxidant molecules present during development, which are strongly influenced by light (Jang et al., 2013; Wu et al., 2016). The antioxidant activities of the extracts of mycelia and fruiting bodies of $L$. swartzii produced under color LEDs and dark condition were determined. Interestingly, mycelial extracts from all color LEDs had higher radical scavenging activities when compared to the positive control, catechin, indicating the very promising potential of LED-grown mycelia of $L$. swartzii as source of antioxidant agents. Fundamentally, the highest scavenging activity and phenolic content of fruiting body could be acquired when grown under red LED. This positive response to red LED could probably be due to the ability of red-light absorbing photoreceptors to receive photons and transduce the photon energy into cells to regulate fungal photoresponses through differential gene expression which can regulate biochemical processes (Kurtzman and Martínez-Carrera, 2013; Correa et al., 2003). Previous works reported a significant influence of LEDs on the antioxidant property of fruiting bodies of mushrooms and of plants. For instance, Pleurotus eryngii and Hericium marmoreus recorded high 
radical scavenging activity when grown in blue LED (Jang et al., 2011; 2013). However, in plants, red LED wavelength increases the antioxidant properties and promotes accumulation of anthocyanin, which can be accounted to the increased gene expression for biosynthesis of anthocyanin (Lekkham et al., 2016). The antioxidants reduce the risk for neurodegenerative, cardiovascular diseases and cancer (Prakash et al., 2001). Noteworthy, the present work showed that mycelial extracts have higher scavenging activity and phenolic content than any of the fruiting body extracts. Moreover, the mycelia and fruiting body have varied responses to different color LEDs.

\section{Conclusion}

The present work has shown that red LED enhances the efficient mycelial biomass production in liquid culture and basidiocarp production of L. swartzii in the rice straw and sawdust-based substrate. Mycelial extracts from the three-color LEDs and the fruiting body extract from red LED exhibited higher radical scavenging activity. The maximum phenolic content of mycelia and fruiting body could be acquired when incubated under green and red LEDs, respectively. Therefore, cultivation of $L$. swartzii cum exposure to red LED is a useful technique in improving biomass production as well as the antioxidant properties of $L$. swartzii. In order to fully maximize the utilization of this technique, extensive studies on the effects of color LEDs to commercially cultivated mushrooms must be carried out.

\section{Acknowledgement}

The authors sincerely thank the Center for Natural Sciences, Saint Mary's University, Bayombong, Nueva Vizcaya, Philippines for their assistance.

Disclaimer: None.

Conflict of Interest: None.

Source of Funding: None.

\section{References}

Alcazar AA, Dulay RMR, Kalaw SP and Reyes RG, 2018. Effect of light emitting diodes on the mycelial biomass production and antioxidant activity of Ganoderma lucidum (W. Curt.: Fr.) P. Karst. 2018 International Conference on Recent Advances in Conservation Biology and
Environment, Central Luzon State University, Science City of Munoz, Nueva Ecija, Philippines. Ambra R, Grimaldi B, Zamboni S, Filetici P, Macino $\mathrm{G}$ and Ballario P, 2004. Photomorphogenesis in the hypogeous fungus Tuber borchii: isolation and characterization of Tbwc-1, the homologue of the blue-light photoreceptor of Neurospora crassa. Fungal Genet. Biol. 41(7):688-697.

Aquino YKDC, Vega LDP, Medrano NRM and Dulay RMR, 2018. Mycochemicals, antioxidant and cytotoxic activities of Polyporus grammocephalus Berk (BIL7749). Int. J. Biol. Pharm. Allied Sci. 7(6):966-975.

Beluhan S and Ranogajec A, 2011. Chemical composition and non-volatile components of Croatian wild edible mushrooms. Food Chem. 124:1076-1082.

Chang ST and Miles PG, 2004. Mushrooms: cultivation, nutritional value, medical effect, and environmental impact (2nd Edition). CRC Press, USA.

Correa A, Lewis ZA, Greene AV, March IJ, Gomer RH and Bell-Pedersen D, 2003. Multiple oscillators regulate circadian gene expression in Neurospora. Proc. Nat. Acad. Sci. U.S.A. 100:13597-13602.

Damaso EJ Jr, Dulay RMR, Kalaw SP and Reyes RG, 2018. Effects of color light emitting diode (LED) on the mycelial growth, fruiting body production, and antioxidant activity of Lentinus tigrinus. CLSU Int. J. Sci. Technol. 3(2):9-16.

Dulay RMR, Andres SMB, Asuncion AFC, Calalang AS and Cumbe AP, 2017a. Mycelial biomass production and radical scavenging activity of Lentinus tigrinus in submerged cultivation using selected tropical fruit juice. Int. J. Biol. Pharm. Allied Sci. 6(11):2154-2161.

Dulay RMR, Arenas MC, Kalaw SP, Reyes RG and Cabrera EC, 2014. Proximate composition and functionality of the culinary-medicinal tiger sawgill mushroom, Lentinus tigrinus (Higher basidiomycetes), from the Philippines. Int. J. Med. Mushrooms. 16(1):85-94.

Dulay RMR, Cabrera EC, Kalaw SP and Reyes RG, 2012c. Optimal growth conditions for basidiospore germination and morphogenesis of Philippine wild strain of Lentinus tigrinus (Bull.) Fr. Mycosphere. 3(6):926-933.

Dulay RMR, Cabrera EC, Kalaw SP, Reyes RG and Hou CT, 2020a. Nutritional requirements for mycelial growth of three Lentinus species from the 
Philippines. Biocatal. Agric. Biotechnol. 23:101506.

Dulay RMR, Cabrera EC, Kalaw SP, Reyes RG and Hou CT, 2020b. Cultural conditions for basidiospoe germination of Lentinus swartzii and Lentinus strigosus and their morphogenesis. Asian J. Agric. Biol. 8(4):377-385.

Dulay RMR, Flores KS, Tiniola RC, Marquez DHH, Dela Cruz AG, Kalaw SP and Reyes RG, 2015. Mycelial biomass production and antioxidant activity of Lentinus tigrinus and Lentinus sajorсајu in indigenous liquid culture. Mycosphere. 6(6):659-666.

Dulay RMR, Kalaw SP, Reyes RG, Cabrera EC and Alfonso NF, 2012b. Optimization of culture conditions for mycelial growth and basidiocarp production of Lentinus tigrinus (Bull.) Fr., a new record of domesticated wild edible mushroom in the Philippines. Philipp. Agric. Sci. 95(3):278285.

Dulay RMR, Miranda LA, Malasaga JS, Kalaw SP, Reyes RG and Hou CT, 2017b. Antioxidant and antibacterial activities of acetonitrile and hexane extracts of Lentinus tigrinus and Pleurotus djamour. Biocatal. Agric. Biotechnol. 9:141-144.

Dulay RMR and Pamiloza DG, 2018. Proximate composition and bioactivities of hairy sawgill mushroom, Lentinus strigosus (BIL 1324) from the Philippines. Int. J. Biol. Pharm. Allied Sci. 7(3):361-369.

Dulay RMR, Parungao AG IV, Kalaw SP and Reyes RG, 2012a. Aseptic cultivation of Coprinus comatus (O. F. Mull.) Gray on various pulp and paper wastes. Mycosphere. 3(3):392-397.

Ghorai S, Banik SP, Verma D, Chowdhury S, Mukherje S and Khowala S, 2009. Fungal biotechnology in food and feed processing. Food Res. Int. 42:577-587.

Ibrahim R, Mohd Aziz K, Mat Arshad A and Hasan SMZ, 2015. Enhancing mushroom production using physical treatments prior to fruiting body formation. Malays. Appl. Biol. 44(1):69-73.

Ibrahim R, Mohd Jamil AAI, Hasan SMZ, Mat Arshad A and Zakaria Z, 2017. Enhancing growth and yield of grey oyster mushroom (Pleurotus sajorcaju) using different acoustic sound treatments. MATEC Web Conf. 97:01054.

Idnurm A and Heitman J, 2005. Light controls growth and development via a conserved pathway in the fungal kingdom. PLoS Biol. 3(4):615-626.
Jang MJ, Lee YH, Ju YC, Kim SM and Koo HM, 2013. Effect of color of light-emitting diode on development of fruit body in Hypsizygus marmoreus. Mycobiology. 41(1):63-66.

Jang MJ, Lee YH, Kim JH and Ju YC, 2011. Effect of LED light on primordium formation, morphological properties, ergosterol content and antioxidant activity of fruit body in Pleurotus eryngii. Korean J. Mycol. 39(3):175-179.

Kalaw SP, Alfonso DO, Dulay RMR, De Leon AM, Undan JQ, Undan JR and Reyes RG, 2016. Optimization of culture conditions for secondary mycelial growth of wild edible mushrooms from selected areas in Central Luzon, Philippines. Curr. Res. Environ. Appl. Mycol. 6(4):277-287.

Kim DH, Choi HJ, Jo WS and Moon KD, 2012. Quality characteristics of Pleurotus eryngii cultivated with different wavelength of LED lights. Korean J. Food Preserv. 19(3):354-360.

Kolak U, Özturk M, Özgokce F and Ulubelen A, 2006. Norditerpene alkaloids from Delphinium linearilobum and antioxidant activity. Phytochemistry. 67(19):2170-2175.

Kurtzman JRRH and Martínez-Carrera D, 2013. Light, what it is and what it does for mycology. Micol. Aplicada Int. 25:23-33.

Lekkham P, Srilaong V, Pongprasert N and Kondo S, 2016. Anthocyanin concentration and antioxidant activity in light-emitting diode (LED)-treated apples in a greenhouse environmental control system. Fruits. 71:269-274.

Olle M and Virsille A, 2013. The effects of lightemitting diode lighting on greenhouse plant growth and quality. Agr. Food Sci. 22(2):223234.

Philippoussis A, Zervakis G and Diamantopoulou P, 2011. Bioconversion of agricultural lignocellulosic wastes through the cultivation of the edible mushrooms Agrocybe aegerita, Volvariella volvacea and Pleurotus spp. World J. Microbiol. Biotechnol. 17:191-200.

Pittarate S, Thungrabeab M and Krutmuang P, 2018. Effect of color of light emitting diodes on the development of mycelial growth, conidiation and UV radiation in Beauveria bassiana (Balsamo) Vuillemin. Int. J. Sci. Res. 7(6):1696-1700.

Prakash A, Rigelhof F and Miller E, 2001. Antioxidant activity. Medical Laboratories Analytical Progress. Retrieved http://www.medlabs.com/Downloads/Antiox_acti _pdf. 
Ragasa CY, Tan MCS, De Castro MEG, De Los Reyes MM, Oyong GG and Shen CC, 2018. Sterols from Lentinus tigrinus. Pharmacogn J. 10(6):10791081.

Reyes RG, Eguchi F, Iijima T and Higaki M, 1998. Physiological considerations for the efficient colonization of fukurotake, Volvariella volvacea. J. Wood Sci. 44:408-413.

Saadatmand S, Khavari-Nejad RA and Namin MN, 2014. Effects of light irradiation on spore germination, spawn run, protein content and fruiting body formation in Pleurotus florida Singer. Int. J. Biosci. 4(9):239-245.

Sogan MM, Maslang JAL and Dulay RMR, 2018. Myco-chemicals and teratogenic activity of wild mushroom Trichaleurina celebica from Mt. Palali, Quezon, Nueva Ecija, Luzon Island, Philippines. CLSU Int. J. Sci. Technol. 3(2):1723.

Starostzik C and Marwan W, 1995. A photoreceptor with characteristics of phytochrome triggers sporulation in the true slime mold Physarum polycephalum. FEBS Lett. 370:146-148.

Sunita M and Dhananjay S, 2010. Quantitative analysis of total phenolic content in Adhatoda vasica Nees extracts. Int. J. PharmTech. Res. 2(4):2403-2406.

Wang L, Chen X, Wang Q, Hao J and Lan J, 2011. Effect of different light of LED light quality on growth and antioxidant enzyme activities of
Ganoderma lucidum. China J. Chinese Materia Medica. 36(18):2471-2474.

Wasser SP and Weis AL, 1999. Medicinal properties of substances occurring in higher basidiomycetes mushrooms: current perspectives. Int. J. Med. Mushrooms. 1:31-62.

Wasser SP, 2002. Medicinal mushrooms as a source of antitumor and immunomodulating polysaccharides. Appl. Microbiol. Biotechnol. 60:258-274.

Wu X, Guan W, Yan R, Lei J, Xu L and Wang Z, 2016. Effects of UV-C on antioxidant activity, total phenolics and main phenolic compounds of the melanin biosynthesis pathway in different tissues of button mushroom. Postharvest Biol. Technol. 118:51-58.

\section{Contribution of Authors}

Tiniola RC: Conceptualization of the study, literature review, experimental design and data collection, manuscript writing Pambid RC \& Bautista AS: Research design and methodology assessment, manuscript critiquing, final reading and approval Dulay RMR: Conceptualization of the study, statistical analysis and data interpretation, manuscript writing 